\title{
Leaf senescence and clonal growth of white clover
}

\author{
S.M. BUTCHER ${ }^{1}$, D.W. FOUNTAIN ${ }^{2}$ and M.T. MCMANUS ${ }^{2}$ \\ ${ }^{1}$ New Zealand Institute for Crop and Food Research, Private Bag 4005, Levin \\ ${ }^{2}$ Dept of Plant Biology and Biotechnology, Massey University, Palmerston North
}

\begin{abstract}
Leaf senescence is a programmed event where resources are mobilised from older tissues to the meristematic regions of the plant. In white clover (Trifolium repens L.), leaf and stolon senescence have an important impact on the persistence of the legume in pasture. As part of our investigation of leaf senescence, we have evidence for a central role for the plant hormone ethylene and have identified genes encoding ethylene biosynthetic enzymes. In this paper we include data showing some physiological changes as leaf tissue undergoes senescence and present evidence for the role of ethylene in regulating this process.
\end{abstract}

Keywords: chlorophyll, ethylene, senescence, stolon, leaf, Trifolium repens $\mathrm{L}$.

\section{Introduction}

Growth of white clover in swards is clonal, and the size of individual plants is dictated by the equilibrium between the rate of stolon formation at the apices, and the rate of death of older basal stolon material (Hay et al. 1988). The clover plant population overwinters with most individuals having a complex branching pattern. In spring, up to $70 \%$ of the total stolon pool senesce mainly from the basal end of stolons. This pattern of senescence in a large complex plant may cause fragmentation leaving several small independent plants. This process results in a shift towards a population with a simpler branching structure (Hay et al. 1989a). However, at this time there is no significant change in the number of plants in the population which suggests that the death rate of these small plants is also high in spring (Hay et al. 1989a). These changes may have a large impact on pasture production as smaller plants are particularly vulnerable to stress during reestablishment (Hay et al. 1988) perhaps due to the significantly decreased starch content. The combination of small plant size and low starch content means the energy reserve of plants in spring is only $10-15 \%$ of those in autumn (Hay et al. 1989b).

Little information is available about the physiological processes involved in stolon senescence. The process is initiated from a node at which an older root dies and encompasses tissue up to the next viable root. Photosynthetic capacity is likely to be an important factor in determining stolon senescence. Studies have shown that stolon senescence is accelerated in severely defoliated plants (Chapman \& Robson 1992). The main sources of photosynthate on stolons are the leaves arising from nodes 3-6 (counting from the apex), although Hoshino (1974) has shown that developing leaves change from being net importers to net exporters once they have reached $65-70 \%$ of their maximum area.

We are undertaking a study to identify the important physiological events involved in leaf senescence in white clover, with a view to understanding senescence processes of stolons. Here, we present evidence that the hormone ethylene is associated with the senescence process, and discuss strategies to exploit our findings to improve the persistence of this important forage legume in pasture.

\section{Methods}

Cuttings with two or three leaves were taken from greenhouse grown stock plants (AgResearch Grasslands genotype $10 \mathrm{~F}$ ) and all leaves were excised at the base of the petiole, except the youngest leaf. The cuttings were placed with the basal node buried in trays of bark- and pumice-based, fertilised, potting mix. The trays were then placed in a timer controlled mist propagation system with $21^{\circ} \mathrm{C}$ bottom heat. The cuttings produced roots within 10-14 days, and were grown on for about four weeks before being potted along the centre line of another tray containing the same potting mix, with five plants per tray. New stolons growing from these "mother" plants were trained over a dry plastic surface so as to prevent root growth. Subsequently, all axillary shoots and flowers were removed. Stolon growth in white clover is indeterminant. Nodes (leaves) are produced at a constant rate depending on environmental factors. In the system described here, the number of leaves per stolon becomes constant as the senescence rate balances the production rate.

Chlorophyll concentration in leaves of ten stolons was measured using the method of Moran and Porath (1980). Evolved ethylene measurements were made from individual leaves, with five replicates, using gas chromatography with a photoionisation detector 
(PhotoVac, Canada). Whole trays of plant were removed from the greenhouse and placed indoors away from direct sunlight. Leaves were enclosed in $30 \mathrm{ml}$ screwtop plastic vials with a notch cut in the lid to accept the petiole. The leaves were placed inside the containers and the petiole notch sealed with petroleum jelly. After 1 hour, a $1 \mathrm{ml}$ gas sample was withdrawn from the container through a rubber bung inserted in the base of the container. Empty containers sealed with petroleum jelly were used as a control.

\section{Results}

When stolons are grown using this system, a leaf developmental series from initiation to senescence is observed. Chlorophyll concentration is higher in mature size leaves (leaf number 2) compared with an expanding leaf (leaf number 1) (Figure 1). The concentration then remains stable in leaves two to eight before decreasing rapidly between leaves eight and nine. The concentration remains constant in leaves nine to eleven then declines gradually to leaf seventeen.

Ethylene evolution from leaves mirrors the chlorophyll content (Figure 2). The high level of ethylene evolution from leaf one is consistent with the association of ethylene in leaf expansion (Osborne 1991). Ethylene evolution remains constant from leaves two to six, declines from leaf seven and again remains constant until leaf ten. The level increases rapidly from leaf ten to leaf seventeen. To confirm the association of ethylene with leaf senescence, we have treated excised leaves with ethylene and recorded the time taken to the onset of yellowing (senescence). In these experiments, we observed a differential response to the hormone with older leaves (arising from nodes 4-6) yellowing rapidly when compared with younger mature green leaves (data not shown).

\section{Discussion}

This work has shown that ethylene is associated with leaf senescence in white clover. Ethylene is involved in many plant processes including senescence of leaves, fruit and flowers (Picton et al. 1993; Woodson et al. 1992) and is therefore likely to be involved in the senescence of stolons. Ethylene is not considered to be the 'trigger' of senescence but has a promoter effect in increasing the rate at which some senescence associated changes occur (Smart 1994). Blocking the action of ethylene (e.g. 2, 5 norbornadiene) or interfering with ethylene reception (e.g. silver ions), or blocking the production of ethylene with inhibitors or anti-sense RNA technology has been used to reduce the promotive effects of this hormone on senescence processes. For example,
Figure 1: Mean total chlorophyll concentration. One is the leaf nearest the stolon apex. Vertical bars represent $t$ standard error.

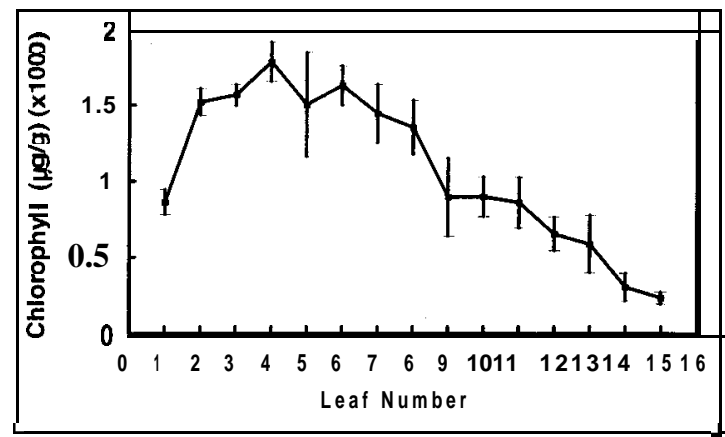

Figure 2: Mean ethylene evolution from clover leaves. One is the leaf nearest the stolon apex. Vertical bars represent t/. standard error.

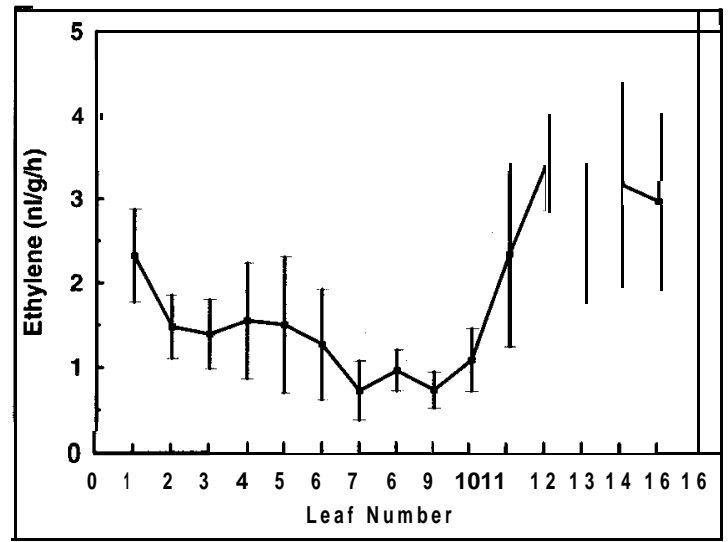

in tomato leaves, reducing the production of ethylene using anti-sense technology has decreased the rate of senescence in leaves (John et al. 1995).

In plants, ethylene is formed via the Yang cycle from the precursor molecule 1-aminocyclopropane-1carboxylic acid (ACC) (Yang \& Hoffmann 1984). Two enzymes are involved in the committed part of the pathway; ACC-synthase which converts s-adenosyl methionine (SAM) to ACC, and then ACC-oxidase which converts ACC to ethylene. We have analysed ACC-oxidase activity for individual leaves and found activity is maintained in all leaves including those with low levels of ethylene evolution. However, we could not measure ACC-synthase activity as the activity remained below the detection level of the instruments used. Together, these data support the hypothesis that the conversion of SAM to ACC by ACC-synthase is the rate limiting step in ethylene production in leaves of 
white clover, a phenomenon that has been widely reported for other tissues (Zarembinski \& Theologis 1994). We are currently using polymerase chain reaction (PCR) based approaches to generate molecular probes to ACC-synthase and ACC-oxidase. A cDNA library has also been prepared and full length cDNA clones for ACC-synthase are being isolated.

In pasture, two strategies to reduce the influence of ethylene on senescence appear possible; breeding for low ethylene production and/or low ethylene perception, and genetically engineering plants to reduce ethylene production or perception. The breeding programmes require the identification of suitable genes in natural populations. This work has identified the role of ethylene in leaf senescence, and the cloning of the biosynthetic genes (ACC-synthase and ACC-oxidase) will allow a number of approaches to study senescence in clover. In particular, these clones can be used as probes to identify the early changes to senescence in leaves and stolons, and can also be used to provide anti-sense constructs to reduce ethylene production in clover. The technology to introduce gene constructs into elite genotypes of white clover is now available (Voisey et al. 1994).

The longer-term aim of this molecular approach is to delay senescence in the basal stolon material of clover in pastures. Such a strategy should improve pasture production during the critical early spring growth period.

\section{Acknowledgements}

We thank Dr John Caradus for providing plant material, Dr Mike Hay for discussions on the project, and the New Zealand Institute for Crop and Food Research for the provision of the study grant to S.M.B.

\section{References}

Chapman, D.F.; Robson, M.J. 1992. The physiological role of old stolon material in white clover (Trifolium repens L.). New Phytologist 122: 53-62.

Hay, M.J.M.; Brock, J.L.; Thomas, V.J.; Knighton, M.V. 1988. Seasonal and sheep grazing management effects on branching structure and dry weight of white clover plants in mixed swards. Proceedings of the New Zealand Grassland Association 49: 197201.
Hay, M.J.M.; Brock, J.L.; Thomas, V.J. 1989a. Characteristics of individual white clover plants in grazed swards. Proceedings International Grassland Congress 16: 1051-1052.

Hay, M.J.M.; Chu, A.C.P.; Knighton, M.V.; Wewala, S. 1989b. Variation with season and node position in carbohydrate content of white clover stolons. Proceedings International Grassland Congress 16: 1059-1060.

Hoshino, M. 1974. Translocation and accumulation of assimilates and phosphorus in Ladino clover. Bulletin of the National Grassland Research Institute (Japan) 5: 35-84.

John, I.; Drake, R.; Farrell, A.; Cooper, W.; Lee, P.; Horton, P.; Grierson, D. 1995. Delayed leaf senescence in ethylene-deficient ACC-oxidase antisense tomato plants: molecular and physiological analysis. The Plant Journal 7: 483-490.

Moran, R. and Porath, D. 1980. Chlorophyll determination in intact tissues using $\mathrm{N}, \mathrm{N}$-dimethylformamide. Plant Physiology 65: 478-479.

Osborne, D.J. 1991. Ethylene in leaf ontogeny and abscission. pp. 194-214. In: Mattoo, A.; Suttle, J.C. (eds). Ethylene. CRC Press, Boca Raton, Florida, USA.

Picton, S.; Barton, S.L.; Bouzayen, M.; Hamilton, A.J.; Grierson, D. 1993. Altered fruit ripening and leaf senescence in tomatoes expressing an antisense ethylene-forming enzyme transgene. The Plant Journal 3: 469-481.

Smart, C.M. 1994. Tansley Review No. 64: Gene expression during leaf senescence. New Phytologist 126: 419-448.

Voisey, C.R.; White, D.W.R.; Dudas, B.; Appleby, R.D.; Ealing, P.M.; Scott, A.G. 1994. Agrobacteriummediated transformation of white clover using direct shoot organogenesis. Plant Cell Reports 13: 309314.

Woodson, W.R.; Park, K.Y.; Drory, A.; Larsen, P.B.; and Wang, H. 1992. Expression of ethylene biosynthetic pathway transcripts in senescing carnation flowers. Plant Physiology 99: 526-532.

Yang, S.F.; Hoffman, N.E. 1984. Ethylene biosynthesis and its regulation in higher plants. Annual Review of Plant Physiology 35: 155-189.

Zarembinski, T.I.; Theologis, A. 1994. Ethylene biosynthesis and action: a case for conservation. Plant Molecular Biology 26: 1579-1597. 
